\title{
Integrated Reservoir Management: A Powerful Method to Add Value to Companies' Assets. A Modern View of the EOR Techniques
}

\author{
F. Kalaydjian ${ }^{1}$ and B. Bourbiaux ${ }^{1}$ \\ 1 Institut français du pétrole, 1 et 4, avenue de Bois-Préau, 92852 Rueil-M almaison Cedex - France \\ e-mail: francois.kalaydjian@ifp.fr - bernard.bourbiaux@ifp.fr
}

Résumé - Gestion intégrée des réservoirs : une méthode performante pour accroître la valeur des réserves des compagnies pétrolières. Une conception moderne des méthodes de récupération assistée - La gestion intégrée des réservoirs est une méthode attractive permettant d'accroître la valeur des réserves des compagnies pétrolières. Augmenter les réserves de gisements en cours de production par l'utilisation d'une stratégie de développement optimisée constitue en effet, pour les compagnies pétrolières, une réelle opportunité et une alternative intéressante à des campagnes d'exploration coûteuses et risquées.

La gestion intégrée des réservoirs est, dans son principe, une façon de combiner des méthodologies et des technologies telles que la caractérisation de réservoir, l'utilisation d'architectures complexes de puits, les méthodes avancées de mesures pétrophysiques, le monitoring des réservoirs, ou encore, la simulation de réservoir, et de créer entre elles une réelle synergie.

Du fait des avancées très significatives observées dans le domaine de l'informatique, la gestion intégrée des réservoirs se conçoit également comme une gestion en temps réel. L'énorme quantité d'informations acquises durant la production d'un réservoir peut ainsi être utilisée pour développer la compréhension de son organisation, remettre à jour le modèle géologique qui le décrit, réduire les incertitudes, concevoir l'architecture de production la plus appropriée, garantir la productivité et l'injectivité des puits, identifier et cibler des poches d'huile non drainées, sélectionner le procédé de récupération le plus adapté dans le but final d'accroître le taux de récupération.

La plupart des éléments d'une telle stratégie sont déjà disponibles, mais ce qu'il reste à développer est la façon de les combiner afin de construire un réel système intégré. Celui-ci constituera certainement un outil majeur dans la panoplie de l'ingénieur de production de demain.

Dans cet article, nous passons en revue et illustrons les différents ingrédients de ce système intégré.

Abstract - Integrated Reservoir Management: A Powerful Method to Add Value to Companies' Assets. A Modern View of the EOR Techniques - Integrated reservoir management is an attractive process to add value to the oil companies' assets. Indeed, increasing the reserves of their reservoirs already in production through an improved development strategy constitutes for the oil companies a real opportunity and an economic alternative to costly and risky exploration surveys. 
Integrated reservoir management is basically a way of combining complementary approaches and techniques such as reservoir characterization, use of complex well architecture, special core analysis design of recovery processes, reservoir monitoring and reservoir simulation, and creating a positive synergy between them.

Thanks to the advances that have been observed in the domain of the computer science, reservoir management means also real time management. Thus, the large amount of data acquired can be while producing a reservoir used to develop the knowledge of the reservoir, update the reservoir model, reduce the underlying uncertainties, design the most suitable production architecture, ensure the productivity and the injectivity of the wells, target bypassed zones, select the most appropriate recovery process, and hence, increase the overall recovery.

Most of the ingredients of such a strategy are already available. What still needs to be developed is a productive way of linking those ingredients together to build an integrated system. Such a system, when made available will constitute a major toolkit in the toolbox of the production engineers.

In this paper, we review and illustrate the different ingredients that have to be included in such an integrated system.

\section{IN TRO DUCTIO N}

Increasing the recovery of the reservoirs has always been a concern for oil companies. Indeed, complementarily to what costly and risky exploration surveys can add as new reserves, a way for the oil companies to increase their reserves is to improve the recovery factor of the reservoirs they are currently producing.

Twenty years ago, enhancing oil recovery meant designing a specific advanced recovery method, such as a polymer or miscible flooding [1]. With only a partial knowledge of the structure of a given reservoir, the strategy to increase the recovery factor often relied on the hope to find an appropriate recovery process or even a product to be injected which would improve the sweeping efficiency, either by modifying the mobility ratio (polymer flooding) or by lowering the interfacial tension with the oil (surfactant or miscible gas flooding).

The reservoir engineer relied mainly on the result of the reservoir simulations which were taken for granted. Some good success was met sometimes. Some quite disappointing jobs were also recorded and required to frequently revisit the reservoir model to match unexpected production results. Poor predictivity of the reservoir simulations was mainly due to the fact that the reservoir architecture, e.g. the distribution of the producing lithofacies, was poorly understood or poorly accounted for in the reservoir simulations. Uncertainties in the geological model were not considered as building the main contribution to the overall uncertainty in the management strategy of a given reservoir.

The following years were characterized by a depressed oil market which led the oil industry to draw the best profit of existing techniques. Cost reduction objectives became the leitmotiv of many development projects and led to major progress in techniques and practices which, previously, were not considered as factors of oil recovery enhancement. Nowadays, EOR is acknowledged as resulting from the synergy of new and advanced techniques on one hand and integrated reservoir management approaches on the other hand.

In addition to cost reduction the oil companies are faced - from day one-with the necessity to shorten the time spanning between the appraisal and the production of the first oil or required when comes the decision to redevelop a field or produce its satellites. As such, instead of being worked out in a successive manner, projects have to be executed by multidisciplinary teams using sometimes parallel engineering methods. Therefore, for some years, the geologists, geophysicists, petrophysicists and reservoir engineers have learned how to work together in multidisciplinary teams to tackle both exploration and production issues.

To this end, it was necessary for them to share a common language and common concepts. Recently, new tools showed up to help that collaborative work. They are the reality centers. Through the integration of the various softwares which are being used in reservoir characterization and reservoir simulation they do allow to visualize in $3 \mathrm{D}$ the structure of the reservoirs as well as the displacement of the fluids. In the same room, the different members of a team can test various development scenarios, quantify the associated productions and eventually come to an optimum.

Shortening the time required to make decisions will lead in a near future to define not only an improved but a real time reservoir management. Already, the concept of an "electric field" has been defined [2]. It consists in acquiring on a regular basis measurements on various parameters such as pressure or temperature but also variation in saturation through the use of time lapse (or 4D) seismics. It will consist also as soon as some significant progress will have been made in that respect, in triggering down-hole intelligent completions and modify thus in real time the production schemes to optimize the daily production. 
The reservoir management process becomes thus an actual dynamic process. While acquiring data during the exploration stage, then the production stage, the reservoir knowledge about its structure, its ability to be flooded by the fluids is increased. This helps in updating the modeling of the reservoir and improves the reliability of the production forecasts.

\section{THE RESERVO IR MANAGEMENT ISSUES}

Basically, there are five main contributors to an integrated reservoir management:

- well design and management;

- reservoir characterization;

- reservoir modeling;

- surface facilities design;

- economics.

In the following, we will insist on the first three.

Integrating those three items allows to propose and design efficient and economic ways of producing reservoirs and add value to companies assets (as schematically represented in Figure 1).

\subsection{Well Design and Management}

In order to optimize the production and increase the reserves, the exploitation of the reservoirs through complex wells [3] (horizontal wells, ERD (Extended Reach Drilling) wells, multibranched wells) has become the common practice. The major drilling progress performed during the last ten years has led to multiple options for well design: stacked multibranch well, dual opposing laterals, re-entry laterals from a vertical well, cluster well, multidrain or multilateral well, even 3D wells for reservoirs with a complex structure or sparsely-distributed reservoir bodies. Such wells have many advantages over conventional vertical wells:

- their injectivity/productivity is increased and their investigated area is larger, which allows to drill fewer wells;

- they enable to add reserves to difficult fields, characterized by thin reservoirs for instance;

- and they increase the benefit of EOR methods since they provide higher sweep efficiencies.

Guaranteeing the injectivity/productivity of those wells is a major issue as well. It is thus required to prevent as much as possible or remediate to any impairment (due to the invasion of drilling and completion fluids, particle deposition and retention). For this reason, well productivity and injectivity restoration has to be part of the project implementation plan, especially for open-hole complex wells [4]. The design of improved remediation methodologies can be optimized using a laboratory approach that contributes to improve the physical understanding and modeling of well productivity and injectivity. Regarding implementation plan, actions include:

- the use of breakers to overcome cake barrier;

- stimulation procedures involving acid fracturing and matrix acidizing;

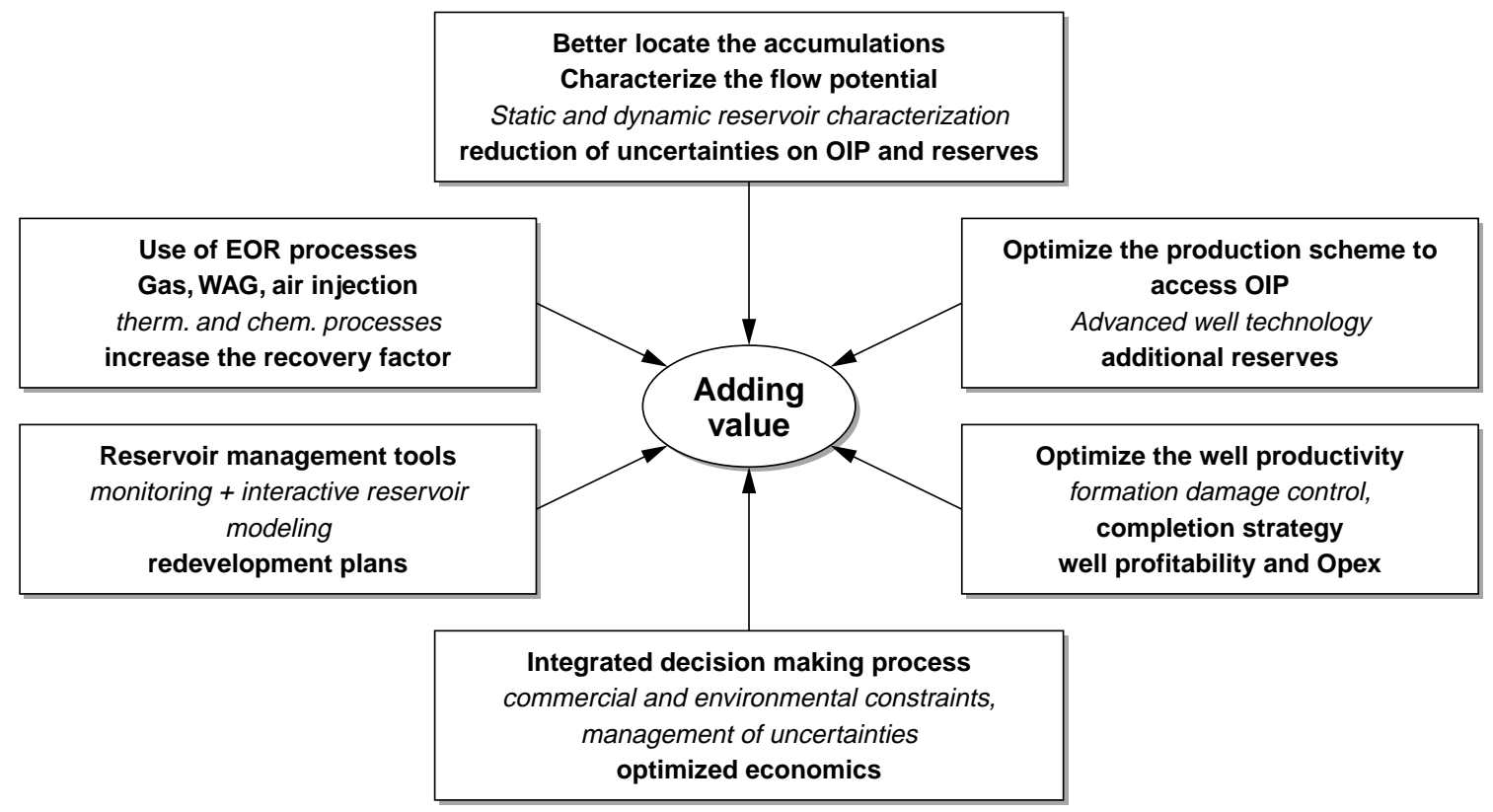

Figure 1

Adding value to companies' assets. 
- well treatment by gels to prevent massive water or gas production, a drastic requirement for optimizing surface treatment facilities;

- and also an overall management of well rates at reservoir scale.

Complex wells combined with conventional and EOR processes such as gas injection, viscous flooding or thermal flooding represent new opportunities for mature fields. Let us consider the polymer flooding method. The very long trajectories of complex wells minimize the risks of polymer degradation because of lower flow rates around the injector, whereas their injection rate remains higher than that of a vertical well. Thus, fewer injectors are required and moreover, the method can be applied to reservoirs having lower permeability than the limit imposed by vertical wells.

To end with, a detailed modeling of the well neighborhood using unstructured grids and improved PI's (Productivity Index Formulations) [5] is useful for assessing well impairment and predicting well productivity/injectivity remediation efficiency. Such a modeling has to take into account the complex flow geometry around the well (perforation effects, etc.) as well as possible multiphase flow effects, with a proper calibration from laboratory experiments [6].

\subsection{Reservoir Characterization}

The objective of reservoir characterization is to improve the geological modeling of the reservoir, hence reduce the subsequent uncertainties in the reservoir model and to assign dynamic properties to the grid blocks at the fine scale in order to reduce the uncertainties in the production forecast. The deliverable of the reservoir characterization is a detailed reservoir model which will then be converted into a flow simulation model through an upscaling process. The reservoir characterization utilizes two main methods: the structural and the stratigraphic modeling.

Concerning structural modeling, interactive modeling software now helps checking the consistency between seismic-derived horizons and faults, and the observations made in wells. Regarding the stratigraphic modeling, logs and core information are now used in an integrated way to derive rocktypes based on both geological and petrophysical criteria. In practice, a statistical multivariable analysis of well logs is performed and the resulting crossplots are analysed jointly with core petrophysical data in order to identify rocktypes.

The benefits of this approach are twofold:

- the use of information available in all wells, logs;

- the calibration of geological facies in terms of flowproperties information available in few cored wells. Thus, the identified rock-types remain meaningful for both the sedimentologist and the reservoir engineer.

The following step consists in integrating the structural and sedimentological information into a geological model (Fig. 2). First, a grid is built based on the interpreted correlations between the main lithostratigraphic units between wells. Then, the cells of this grid are assigned rocktypes and petrophysical properties using geostatistical techniques. The main input of geostatistical simulation is the detailed matrix proportion curves derived from well data. To constrain the geostatistical realization between wells, seismic attributes maps are helpful. Actually, once they have been calibrated at wells, these maps provide a trend in the spatial evolution of vertical facies distribution. Recent improvements in the geostatistical modeling tools include the possibility to simulate several deposition phenomena through pluri-Gaussian simulation and generate given sedimentary structures through object-based simulation.



Structural model

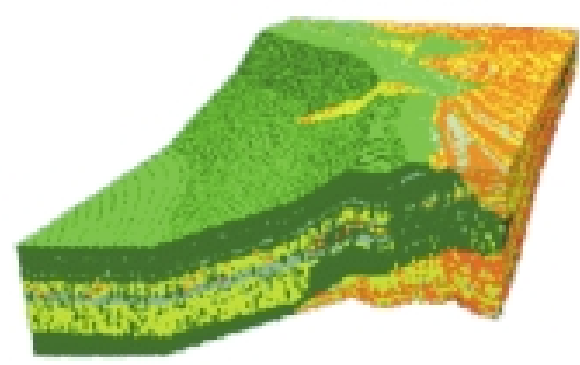

Geological model

Figure 2

From a structural model to a geological model, using the IFP reservoir modeling line. 
Moreover, the integration of dynamic data greatly contributes to the reliability of the geological model for subsequent reservoir applications. This integration can be performed at the initial phase of field development using well tests results. Later on, new dynamic information from wells will enable the updating of the geological model. In practice, advanced mathematical methods are now available to tune the geological model to well test results [7].

They include:

- techniques of inversion of the simulated well tests such as the gradient method, for tuning the petrophysical properties;

- and a gradual deformation technique [8] for tuning the geological model itself, that is facies distribution, reservoir boundaries or faults position.

In the domain of reservoir characterization some complete software lines do exist. This is the case for the IFP with its Reservoir Modeling Line (RML).

\subsection{Reservoir Modeling}

Subsequent to geological model construction and calibration, upscaling procedures are applied to build a coarse-grid reservoir model required for multiphase flow simulation of production. However, the consistency between the reservoir model and the geological model will be maintained thanks to the previous calibration of geological model against petrophysical and dynamic information. This consistency can be reinforced all during the field life by the integration of new dynamic data and/or special core analysis (SCAL) studies.

Those studies consist in performing the required laboratory experiments (mainly the measurements of relative permeabilities and capillary pressures) at the actual reservoir conditions in order to honor the fluid properties, the wettability conditions, the saturation end-points. Though much more complex and time consuming than routine laboratory studies, the SCAL results are much more reliable to calibrate the reservoir model. Specific procedures and equipments have been developed for that purpose [9].

The role of the flow units defined at reservoir model scale can then be easily related to the distribution of rocktypes in the detailed geological model.

In order to be adapted to various development schemes, the reservoir simulator has to be implemented with a number of options. As such, the reservoir simulator must account for rock mechanical effects (especially to tackle fractured reservoirs), include a dual-media option $[10,11]$ (for the same reason), be coupled to a surface model in order to allow a global optimization process, be designed to simulate compositional effects like with gas injection and handle chemical or thermal flooding. With regard to complex well compliance and modeling of heterogeneities, the simulator has to be implemented with unstructured gridding facilities. Finally, in order to make it possible to perform heavy computations and be used for making rapid decisions, the simulator must be able to be run on parallel machines.

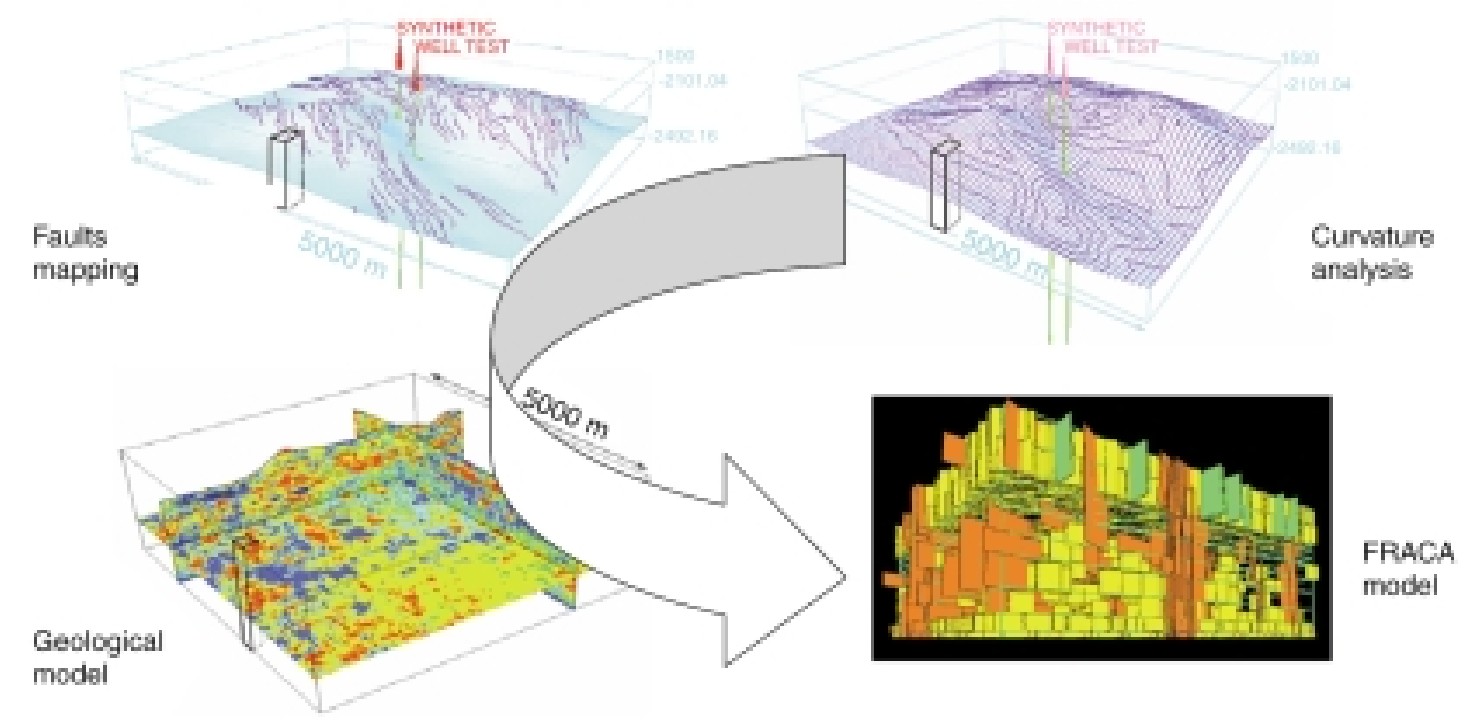

Figure 3

Fractured reservoir modeling, the IFP FRACA methodology. 
The ATHOS reservoir simulator has been developed by IFP to this end and is implemented with those options [12].

Before ending, a special attention has to be given to the modeling of fractured reservoirs. For such reservoirs, various information have to be collected at different scales, for fracture analysis, modeling then upscaling to reservoir cell scale:

- structural information derived from seismic data;

- core and log data, in particular, borehole images;

- and production logs for assessing the role of fractures on flow.

In practice, integrated software package (such as FRACA [13] developed by $I F P$ ) are used to define the fracturing style and then model the fault/fracture distribution within the reservoir:

- maps of fracture attributes such as density are generated using various techniques including curvature analysis and interpolation between wells;

- a discrete model of sub-seismic faults can be generated using fractal analysis;

- and, finally, these interpreted data can be combined with the geological model to generate a stochastic model of the fracture network at any position within the reservoir (Fig. 3).

Building a reliable model of the reservoir will considerably help the design of the production scheme and of a specific EOR method, by minimizing the risks associated with uncertainties on accumulations and reserves. Some specific methodologies to quantify uncertainties were developed. A powerful one is based on the experimental design approach.

The principle as quoted in [14] is "to get the maximum information at the lowest experimental cost by varying all the uncertain parameters simultaneously. In (this) case, the physical process is replaced by the reservoir simulator". The method consists in launching the reservoir simulator for the sets of parameters which have been selected by the experimental design technique. The following step consists in building a simple model of the response of the system. This model will match the response of the system at the selected experimental points, then will interpolate between them. In the space of the parameters, a surface will thus be built. That is the Response Surface Methodology (RSM). Then, depending on the objective (maximizing the plateau duration, minimizing the development cost, etc.), the reservoir engineer will use the RSM approach to find the optimal solution. As the parameters are known with a given uncertainty, the result will be an estimate as well. This method has been successfully applied to the quantification of the uncertainties on the cumulative oil production of a field case.

In principle, it is then possible to link the reservoir simulator to an economic software and derive an economic evaluation of various development schemes.

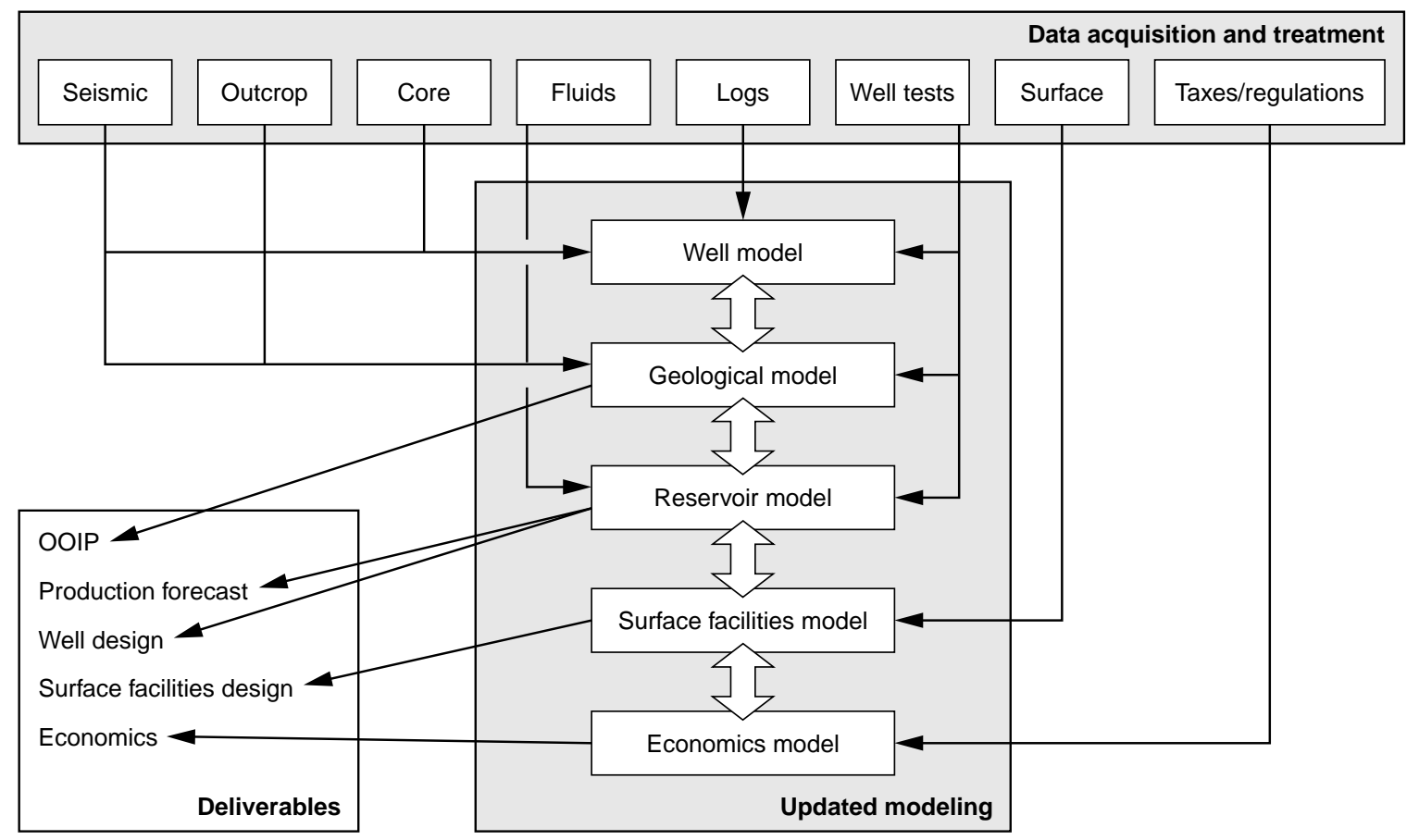

Figure 4

Integrated reservoir management. Organization scheme. 


\section{RESERVOIR MON ITO RIN G}

A stated in the Introduction Section of this paper, the reservoir management duty can be improved a lot by using all the available information that are acquired during the life of a reservoir. The various data which are acquired are displayed in Figure 4. They comprise data which are acquired or used at the very beginning stage of exploration or later on while producing the reservoir.

Those data are used to calibrate, constrain and update the software packages which are linked together to model in a consistent way the well behavior, the geological model, the reservoir model which can be linked to a surface facility model [15] and finally to an economic model.

In addition to the various data which are commonly acquired through downhole gauges of pressure and temperature or flow meter data [16], an impressive way of improving the reservoir surveillance is to use seismic data and build the so-called seismic monitoring [17, 18]. Using 4D (time lapse 3D) seismic data gives rise to the imaging of the fluid movements within the reservoir provided that a treatment like depth conversion be performed.

Using this dynamic reservoir modeling, it is then possible to make further decisions about the development strategy of a given reservoir, such as drilling of new branches of a given complex well or triggering intelligent completions.

All this system leads to perform a real time management. This is certainly how the reservoirs will be operated in the next years. For that purpose software packages will have to be developed to help the reservoir engineers and beyond, the production team to optimize the development of the reservoirs, hence adding value to the companies' assets.

\section{CONCLUSIONS}

In this paper, we have reviewed the main ingredients that take part in an integrated reservoir management, namely the well design and management, the reservoir characterization and the reservoir modeling. This constitutes a modern version of the EOR processes.

The evolution of reservoir management has been discussed. The advances in both technology and computer science should lead in a short term to what is called a real time management based on a careful reservoir surveillance and the ability to make rapid decisions of redevelopment.

Most of the ingredients for that purpose do exist. What is still missing is an efficient software package. For sure, quite soon this gap will be filled. However, quite an important part of the work has not been dealt with in that paper. This concerns the way the information has to be treated, stored in order to allow an efficient processing of it by the different software packages which will have to communicate in a consistent way. This represents the heart of every integrated software solution and will guarantee the success of the approach.

\section{REFEREN CES}

1 Basic Concepts in Enhanced Oil Recovery Processes (1991) Critical Reports on Applied Chemistry, M. Bavière ed., Elsevier Science Publishers LTD, 33.

2 Jack, I. (2001) The e-Field. SPE Paper no. 68189, presented at the 2001 SPE Middle East Oil Show held in Bahrain, 1720 March 2001

3 Renard, G., Morgan, R., Delamaide, E. and Fossey, J.P. (1997) Complex Well Architecture, IOR and Heavy Oils. 15th World Petroleum Congress, Beijing, China, 12-16 October 1997.

4 Longeron, D., Alfenore, J., Salehi, N. and Saintpère, S. (2000) Experimental Approach to Characterize Drilling Mud Invasion, Formation Damage and Cleanup Efficiency in Horizontal Wells with Openhole Completions. SPE Paper no. 58737, presented at the SPE International Conference on Formation Damage, Lafayette, Louisiana, USA, 23-24 February 2000.

5 Jeannin, L., Sarda, S., Ding, D.Y. and Lemonnier, P. (2000) Efficient Finite Volume Schemes Adapted to a New Hybrid Mesh Model in Reservoir Simulation. 7th European Conference on the Mathematics of Oil Recovery - ECMOR VII, Baveno, Lago Maggiore, Italy, 5-8 September 2000.

6 Ding, D., Longeron, D., Renard, G. and Audibert-Hayet, A. (2002) Modelling of Both Near-Wellbore Damage and Natural Cleanup of Horizontal Wells Drilled with a WaterBased Mud. SPE Paper no. 73733, presented at the SPE Formation Damage Control, Lafayette, Louisiana, USA, 2021 February 2002.

7 Blanc, G., Guerillot, D., Rahon, D., Roggero, F. and Helios Reservoir Group. (1995) Building Geostatistical Models Constrained by Dynamic Data - A Posteriori Constraints. SPE Paper no. 35478, presented at the SPE/NPF European Conference, Stavanger, Norway, 16-17 April 1995.

8 Hu, L.H. (2000) Gradual Deformation of Non-Gaussian Stochastic Models. 6th Int. Geostatistics Congress, Cap Town, South Africa, 10-14 April 2000.

9 Fleury, M., Doevle, M. and Longeron, D. (1997) Full Imbibition Capillary Pressure Measurements on Preserved Samples using the Micropore Membrane Technique. SCA Paper, International Symposium of the Society of Core Analysts, Calgary, Canada, 7-10 September 1997.

10 Cosentino, L., Coury, Y., Daniel, J.M., Manceau, E., Ravenne, C., van Lingen, P., Cole, J. and Sengul, M. (2001) Integrated Study of a Fractured Middle East Reservoir with Stratiform Super-K Intervals - Part 2: Upscaling and Dual Media Simulation. SPE Middle East Oil Show \& Conference (MEOS), Bahrain, 17-20 March 2001.

11 Henn, N., Bourbiaux, B., Quintard, M. and Sakthikumar, S. (1999) Modelling Conductive Faults With a Multiscale Approach Involving Segregation Concept. 10th European Improved Oil Recovery Symposium, Brighton, UK, 18-20 August 1999.

12 Magras, J.F., Quandalle, P. and Bia, P. (2001) HighPerformance Reservoir Simulation With Parallel ATHOS. SPE Paper no. 66342, presented at the Reservoir Simulation Symposium, Houston, Texas, USA, 11-14 February 2001.

13 Sabathier, J.C., Bourbiaux, B., Cacas, M.C. and Sarda, S. (1998) A New Approach of Fractured Reservoirs. SPE Paper no. 39825, presented at the SPE International Petroleum 
Conference and Exhibition, Villahermosa, Mexico, 3-5 March 1998

14 Dejean, J.P. and Blanc, G. (1999) Managing Uncertainties on Production Predictions Using Integrated Statistical Methods. SPE Paper no. 56696 presented at the Annual Technical Conference and Exhibition, Houston, USA, 3-6 October 1999.

15 Barroux, C. (2000) Linking Reservoir and Surface Simulators: How to Improve the Coupled Solutions. SPE Paper no. 65159 , presented at the 2000 SPE European Petroleum Conference, Paris, France, 24-25 October 2000.

16 Mezghani, M., van Lingen, P., Cosentino, L. and Sengul, M. (2000). Conditioning Geostatistical Models to Flow Meter Logs. SPE Paper no. 65122, presented at the 2000 SPE
European Petroleum Conference held in Paris, France, 24-25 October 2000.

17 Mjaaland, S., Wulff, A.M., Causse, E. and Nyhavn, F. (2000) Integrating Seismic Monitoring and Intelligent Wells. SPE Paper no. 62878, presented at the 2000 SPE Annual Technical Conference and Exhibition, Dallas, Texas, USA, 1-4 October 2000.

18 O'Donovan, A.R., Smith, S.G. and Kristiansen, P. (2000) Foinaven 4D Seismic - Dynamic Reservoir Parameters and Reservoir Management. SPE Paper no. 63294, presented at the 2000 SPE Annual Technical Conference and Exhibition, Dallas, Texas, USA, 1-4 October 2000.

Final manuscript received in March 2002 